\title{
Application of a new algorithm using Doppler information to retrieve complex wind fields over the Black Sea from ENVISAT SAR images
}

\author{
Alpers Werner ${ }^{1,{ }^{*}}$, Mouche Alexis ${ }^{2}$, Horstmann Jochen ${ }^{3}$, Ivanov Andrei Yu. ${ }^{4}$, Barabanov Vladyslav S. ${ }^{5}$ \\ ${ }^{1}$ Univ Hamburg, Inst Oceanog, Hamburg, Germany. \\ 2 IFREMER, Lab Oceanog Spatiale, Plouzane, France. \\ ${ }^{3}$ Helmholtz Zentrum, Inst Coastal Res, Geesthacht, Germany. \\ ${ }_{5}^{4}$ Russian Acad Sci, PP Shirshov Inst Oceanol, Moscow, Russia. \\ ${ }^{5}$ Marine Hydrophys Inst, Sevastopol, Russia. \\ *Corresponding author : Werner Alpers, email address : alpers@ifm.uni-hamburg.de
}

\begin{abstract}
:
Several algorithms have been proposed to retrieve near-surface wind fields from C-band synthetic aperture radar (SAR) images acquired over the ocean. They mainly differ in the way they retrieve the wind direction. Conventionally, the wind direction is taken from atmospheric models or is extracted from the linear features sometimes visible in SAR images. Recently, a new wind retrieval algorithm has been proposed, which also includes the Doppler shift induced by motions of the sea surface. In this article, we apply three wind retrieval algorithms, including the one using Doppler information, to three complex wind events encountered over the Black Sea and compare the SAR-derived wind fields with model wind fields calculated using the high-resolution weather research and forecasting (WRF) model. It is shown that the new algorithm is very efficient in resolving the $180^{\circ}$ ambiguity in the wind direction, which is often a problem in the streak-based wind retrieval algorithms. However, the Doppler-based algorithm only yields good results for wind directions that have a significant component in the look direction of the SAR antenna. Furthermore, it is dependent on good separation of the contributions to the Doppler shift induced by surface currents and wind-related effects (wind drift and wind-sea components of the ocean wave spectrum). We conclude that an optimum wind retrieval algorithm should consist of a combination of the algorithms based on linear features and Doppler information.
\end{abstract}




\section{Introduction}

The Black Sea is a marine area surrounded by mountains of differing heights with valleys open to the sea. Local winds blowing onto the sea over coastal mountains or through valleys as well as mesoscale atmospheric eddies are often encountered over the Black Sea (Alpers, Ivanov, and Horstmann 2009; Alpers, Ivanov, and Dagestad, 2010, 2011). These local winds, like bora, foehn, and gap winds, interact with the synoptic-scale winds or with each other. Thus, the Black Sea is an ideal test site to validate algorithms to retrieve near-surface wind fields in complex wind environments from synthetic aperture radar (SAR) images. In this study, we apply three different algorithms to retrieve near-surface wind fields from the SAR images. However, we focus on the third one, which is the newly developed algorithm that also uses the Doppler shift of the backscattered SAR signal for wind direction retrieval (Mouche et al. 2012). We apply these algorithms to three complex wind events with winds blowing from different directions over the Black Sea and compare the SAR-derived wind fields using the three algorithms mentioned above to model wind fields calculated using the high-resolution weather research and forecasting (WRF) model (Skamarock et al. 2008). The near-surface wind fields are retrieved from SAR data acquired in 2010 and 2011 by the advanced SAR (ASAR) on board the Environmental Satellite (ENVISAT), which operates in the C-band (5.3 GHz).

\section{Conventional wind retrieval}

For inverting normalized radar cross section (NRCS) values into near-surface wind vectors, one needs a geophysical model function (GMF). In this article, we use the Cband wind scatterometer model function version 4 (CMOD4) (Stoffelen and Anderson 1997) and CMOD version 5 (CMOD5) (Hersbach, Stoffelen, and Dehaan 2007) as GMFs. These two GMFs are practically identical at low to medium wind speed, but differ somewhat at high wind speeds, which is of no relevance to this article. CMOD4 was originally developed to retrieve near-surface wind fields from data obtained from the scatterometers aboard the European Remote Sensing satellites (ERS-1 and ERS-2). While the ERS-1 and ERS-2 scatterometers have a resolution of $50 \mathrm{~km}$ (pixel spacing: $25 \mathrm{~km}$ ), the ASAR aboard the ENVISAT in the wide swath mode (WSM) has a resolution of $150 \mathrm{~m}$ (pixel spacing: $75 \mathrm{~m}$ ). However, for better wind speed estimation, we average over $500 \mathrm{~m} \times 500 \mathrm{~m}$.

Unlike scatterometers, which measure NRCS values of a resolution cell at the sea surface from at least three different azimuth angles, and thus can measure two-dimensional near-surface wind fields, SARs measure them only from one azimuth angle and thus cannot measure near-surface wind vectors directly. However, notwithstanding this drawback, SARs can be used to measure two-dimensional near-surface wind when information on the wind direction is added from sources other than NRCS values. They can be obtained from: (1) atmospheric models (Monaldo et al. 2001 and the references cited therein, 2003; Dagestad et al. 2007), (2) linear features (often, but not always) visible in SAR images (Wackerman et al. 1996; Horstmann et al. 2000; Zecchetto and De Biasio 2008), and (3) Doppler information extracted from the backscattered SAR signal (Mouche et al. 2012).

When using an atmospheric model for wind direction information, in this article we take it from the global atmospheric model provided by the National Centres for Environmental Prediction (NCEP) Global Forecast System (GFS) model. NCEP provides global wind fields every three hours at a grid spacing of $0.5^{\circ}$ in latitude and longitude. Thus, in this case, the direction of the SAR-derived wind field can be resolved only to a 
resolution of the order of $50 \mathrm{~km}$.

In the second algorithm, the wind direction is inferred from linear features (wind streaks), which are often, but not always, visible in SAR images and are assumed to be aligned in the wind direction. Two methods have been developed for retrieving the orientation of the linear features visible in SAR images: (1) the local-gradient method (LG method), which is applied in the spatial domain (Horstmann et al. 2002; Koch 2004) and (2) the fast Fourier transform (FFT) method, which is applied in the spectral domain (Wackerman et al. 1996; Lehner et al. 1998). In this article, we use the LG method and focus on the small-scale linear features that are resolved by SAR and are representative for the near-surface wind direction. Note that the larger-scale features, like those originating from the marine atmospheric boundary layer (MABL) rolls (scale typically a few $\mathrm{km}$ ), are less representative for the near-surface wind direction (Etling and Brown 1993; Alpers and Brümmer 1994; Müller, Brümmer, and Alpers 1999). The direction of the MABL rolls is determined by the mean wind direction in the MABL, which can deviate significantly from the wind direction measured at the sea surface. Note that using the linear-feature algorithm, the wind direction can be retrieved from SAR images only with $180^{\circ}$ directional ambiguity.

\section{Doppler centroid anomaly}

It has been demonstrated by Chapron, Collard, and Ardhuin (2005) that the Doppler centroid anomaly or, in short, the Doppler anomaly (DA), of ENVISAT ASAR data can be used to retrieve geophysical information about both winds and sea-surface currents (Johannessen et al. 2008; Rouault et al. 2010). The DA or residual Doppler results from the line-of-sight motions of the surface scattering elements relative to the fixed earth. Only the component along the SAR look direction is detected. The DA depends on the phase speed of the Bragg waves, the drift current induced by the wind on the sea surface (wind drift), sea state, and ocean surface current (Johannessen et al. 2008). Wind drift and sea state (more precisely the wind-sea part of the ocean wave field) depend on the near-surface wind field, and thus these two contributions together can be used to estimate the wind speed and direction in the look direction of the SAR antenna. An empirical function, called C-band Doppler function (CDOP), which relates the DA at the C-band to surface winds and radar parameters, has been developed by Mouche, Collard, and Kerboal (2010; Mouche et al. 2012):

$$
f^{\mathrm{DA}}=\operatorname{CDOP}\left(\phi, u_{10}, \theta, \mathrm{pol}\right)
$$

Here $\mathrm{u}_{10}$ denotes the wind speed at a height of $10 \mathrm{~m}, \phi$ is the azimuth angle between the look direction of the SAR antenna and the wind direction, $\theta$ is the incidence angle, and $p$ is the polarization of the radar signal.

The CDOP function has been obtained from a three-layer neural network analysis by comparing a large number of wind products obtained from the Advanced Scatterometer (ASCAT) aboard the European Meteorological Operational Satellite (MetOp). DA data are available on a regular basis in ENVISAT ASAR WSM products as auxiliary data since July 2007 . The pixel spacing in the azimuth direction is about $8 \mathrm{~km}$ and in range it varies between $8 \mathrm{~km}$ (in near range) and $3.5 \mathrm{~km}$ (in far range). The accuracy of the DA is about $5 \mathrm{~Hz}$ corresponding to a horizontal velocity change of $0.2 \mathrm{~m} \mathrm{~s}^{-1}$ at an incidence angle of $40^{\circ}$ and of $0.4 \mathrm{~m} \mathrm{~s}^{-1}$ at an azimuth angle of $20^{\circ}$. CDOP coefficients have been published by Mouche et al. (2012).

The DA is interpreted as the mean line-of-sight velocity of the radar backscatter elements (facets). According to the composite surface model for radar backscattering 
(Wright 1968; Valenzuela 1978), both small-scale waves (Bragg waves) and long-scale waves contribute to the observed DA: the first ones contribute via the phase velocity of Bragg waves, and the second ones via the modulation of the Bragg waves by tilt and hydrodynamic modulations (Keller et al. 1994). In addition, scatter elements with steep slopes, as often encountered during high sea states, also contribute to the DA. Because of the multiscale property of the sea surface, the relative weight of the different scattering mechanisms is strongly dependent on radar parameters, such as incidence angle, frequency, and polarization. In the range of incidence angles considered here, the ocean surface waves responsible for the radar backscattering at low to moderate sea states are short gravity waves whose wavelength is given by the Bragg resonance condition (Valenzuela 1978). The wavelength of these so-called Bragg waves decreases with increasing incidence angle and thus - according to the dispersion relation of gravity waves - their phase velocity also decreases. The phase velocity of the Bragg waves decreases with increasing incidence angle, which implies that their contribution to the DA decreases with increasing incidence angle. Furthermore, since the wavelength of the Bragg waves is inversely proportional to the radar frequency, the DA also decreases with radar frequency.

Another observation is that the DA is larger at horizontal polarization $(\mathrm{HH})$ for transmission and reception than for vertical polarization (VV). The reason for this is that the measured DA is the sum of DAs of a large number of scatter elements or facets located in a Doppler resolution cell. The contribution from each scatter element is weighted by its individual NRCS. Since the NRCS as a function of incidence angle is (in the incidence angle range considered here) much steeper for $\mathrm{HH}$ polarization than for VV polarization, we obtain the result that the DA is larger for $\mathrm{HH}$ than for VV polarization. The physical reason for this is as follows: in the presence of long ocean waves, there exists for each facet in a Doppler resolution cell that has a Doppler $\mathrm{f}^{\mathrm{DA}}$, a corresponding 'mirror' facet with the opposite Doppler $-\mathrm{f}^{\mathrm{DA}}$. If both facets had the same NRCS, then their contribution to the mean DA would be zero. However, due to the tilting of the facets by the long waves, both facets are seen by the radar at different incidence angles and, since the NRCS depends on the incidence angle, the NRCSs of the two facets are different. This difference is larger for $\mathrm{HH}$ polarization than for VV polarization due to the fact that the NRCS curve as a function of incidence angle has, in the incidence angle range considered here, a larger slope for $\mathrm{HH}$ than for VV polarization. In addition, scatter elements with steep slopes, as encountered often in high sea states, also have an impact on the Doppler. As shown by Kudryavtsev et al. (2003), their contribution to the Doppler is larger for $\mathrm{HH}$ than for VV polarization.

\section{Wind retrieval including Doppler information}

Portabella, Stoffelen, and Johannessen (2002) first proposed a methodology to combine SAR information with a priori information, taking into account that all sources of information (both observations and models) may contain errors. Mouche et al. (2012) have extended this method by adding information contained in the Doppler shift of the backscattered radar signal. Simultaneous observations of the NRCS (or $\sigma^{\circ}$ ) and Doppler shift $\left(\mathrm{f}^{\mathrm{DA}}\right)$ are assumed to be independent and related to the wind vector $\mathrm{u}$ by the CMOD5 and CDOP transfer functions, respectively. It is assumed that the errors of the observational and model data have Gaussian distributions. This leads to a minimization problem for the determination of the maximum probability to get a wind vector $u$ from the measured $\sigma^{\circ}$ and $\mathrm{f}^{\mathrm{DA}}$ values: 


$$
J(\boldsymbol{u})=\underbrace{\left(\frac{\sigma^{0}-(\mathrm{CMOD})(\boldsymbol{u})}{\Delta \sigma^{0}}\right)^{2}}_{\text {NRCS term }}+\underbrace{\left(\frac{f^{\mathrm{DA}}-(\mathrm{CDOP})(\boldsymbol{u})}{\Delta f^{\mathrm{DA}}}\right)^{2}}_{\text {Doppler tam }}+\underbrace{\left(\frac{\boldsymbol{u}-\boldsymbol{u}_{\mathrm{B}}}{\Delta \boldsymbol{u}}\right)^{2}}_{\text {A priorinodel tem }}
$$

Here $\mathbf{u}_{\mathrm{B}}$ is the a priori wind vector given by the atmospheric model (here by the NCEP model), and $\Delta \sigma^{\circ}, \Delta \mathrm{f}^{\mathrm{DA}}$, and $\Delta \mathrm{u}$ are the Gaussian standard deviation errors for the NRCS, the Doppler shift, and the model wind vector, respectively. Errors in CMOD5 or CDOP and the atmospheric model are expected to be spatially correlated, but this is neglected in this inversion scheme.

\section{Simulations using the WRF model}

We will compare the wind fields derived from the SAR images with simulated wind fields calculated using the WRF model version 3.4.1 (Skamarock et al. 2008). We use a triply nested grid technique with $27 \mathrm{~km}, 9 \mathrm{~km}$, and $3 \mathrm{~km}$ resolution domains and 27 vertical levels. The inner domain with $3 \mathrm{~km}$ resolution covers almost all the eastern half of the Black Sea. The model is initialized by using data provided by the Global Data Assimilation System (GDAS) of NCEP. The final run (FNL) of GDAS provides meteorological data globally four times per day (at 00, 06, 12, and 18 UTC), which are archived at the National Climatic Data Centre (NCDC). We initialize our model runs by using data from the $1^{\circ} \times 1^{\circ}$ GDAS/FNL analyses. For the parameterization scheme, we use the default values of the WRF model. Cumulus cloud convection is not parameterized for the inner domain, but for the two outer domains (Kain 2004).

\subsection{The wind event on 16 January 2011}

Figure 1 shows a subscene of the ENVISAT ASAR image, which was acquired in the WSM mode at VV polarization (vertical for transmission and reception) at 1919 UTC (2219 local standard time) on 16 January 2011 during an ascending satellite pass (see the inset). It shows radar signatures of a complex wind field over the Black Sea. The weather maps of 16/17 January 2011 (not reproduced here) show that a cold front was crossing the Black Sea from north to south. Figure 2(a) shows the near-surface wind field derived from this ASAR image using the wind direction from the NCEP model valid for 1800 UTC on 16 January 2011, i.e. 1 hour and 19 min before the SAR image was taken. It shows a wind front in the upper part of the image. To the north of the wind front, in the western section (in the area with the black arrow inserted), a strong wind of 8 and $12 \mathrm{~m} \mathrm{~s}^{-1}$ was blowing from the northeast. To the south of the wind front (in the area with the white arrow inserted), a weak wind of around $4 \mathrm{~m} \mathrm{~s}^{-1}$ was blowing from the same direction. This is unrealistic, and we attribute it partially to the time difference between the SAR data acquisition and the time for which the wind field was calculated by the NCEP model (1800 UTC). To the east (in the area with the red arrow inserted), it shows a wind blowing from a southwesterly direction towards the coast. Figure 2(b) shows the wind field derived from the ASAR image using linear features for wind direction determination (LG method). No linear features could be detected in the western section of the Black Sea south of the front and thus no wind field could be retrieved from the SAR image in this area. However, to the east (in the area with the red arrow inserted), Figure 2(b) shows a wind blowing from a northeasterly direction towards the coast. This is opposite to the wind direction retrieved 
from the ASAR image using the wind direction from the NCEP model. In Figure 3(a), the radial surface velocity inferred from the Doppler shift is depicted. The sign convention is such that the positive (negative) Doppler velocities are velocities directed eastward (westward). When incorporating this Doppler information into the wind retrieval algorithm, we obtain the wind field map depicted in Figure 3(b), which shows a quite different wind field from that in Figure 2(a). In particular, on this map, in the western section south of the front, the wind blows in an easterly direction, while on the wind field map depicted in Figure 2(a), it blows in a southwesterly direction (see white arrows). Another area, where the three algorithms yield different wind directions, is the area at the north eastern coast of the Black Sea marked by a red arrow. Here, the first algorithm (using NCEP, Figure 2(a)) and the third one (using Doppler, Figure 3(b)) show onshore winds, while the second algorithm (linear features, Figure 2(b)) shows offshore winds.

When comparing the near-surface wind fields calculated by the three wind retrieval algorithms (Figures 2(a), (b), and 3(b)) with the simulated wind field (Figure 4), we see that, in general, they match reasonably well, but there are some areas with pronounced differences. The algorithm using the Doppler information yields opposing wind directions on both sides of the front in the western section of the Black Sea (Figure 3(b)), which is in agreement with the simulated wind field (Figure 4), but it shows onshore winds at the northeastern coast of the Black Sea (marked by a red arrow), which is in disagreement with the simulated wind field. In this area, the algorithm using linear features (Figure 2(b)) yields the correct wind direction.

\subsection{The wind event on 21 June 2011}

Figure 5(a) shows a subscene of the ENVISAT ASAR WSM (VV polarization) image, which was acquired over the Black Sea at 0746 UTC (1146 local standard time) on 21 June 2011 during a descending satellite pass (see the inset). Visible in the southern section is a sharp boundary between areas of low and high image intensity, which is caused by the cold front passing the Black Sea as confirmed by the weather maps of 21 June (not reproduced here). Here, we shall focus on the bright band (the band of high image intensity) attached to the coast visible in the central eastern section of the image. Figure 5(b) shows a zoom on this area. Note that to the northwest of the Russian town Tuapse (location marked by an arrow), the height of the coastal mountain range drops from about $1000 \mathrm{~m}$ to $500 \mathrm{~m}$, which acts as a boundary between wind blocking and wind passage.

Figure 6(a) shows the near-surface wind field derived from this ASAR image using the wind direction from the NCEP model valid for 0900 UTC on 21 June 2011, i.e. 1 hour and 14 min after the ASAR image was acquired, and Figure 6(b) shows the one derived from the ASAR image using linear features for wind direction determination (LG method). These two wind maps show opposing wind directions in the wind tongues (red arrows), but the same directions in the area northwest of the wind tongue (dark arrows). Another area where the two SAR-derived wind fields differ considerably is the area marked A in Figures 6(a) and (b), where not only the wind directions differ (by approximately $45^{\circ}$ ), but also the wind speeds (by approximately $5 \mathrm{~m} \mathrm{~s}^{-1}$ ). Since the wind speed retrieval from SAR images depends on the wind direction, errors in the wind direction lead to errors in wind speed as discussed in detail in the article by Lehner et al. (1998). In this case, the wind field derived from the SAR image using linear features (Figure 6(b)) should best represent the actual wind field. 
In Figure 7(a), the radial surface velocity inferred from the Doppler shift is depicted. It shows that in the wind tongue area the sign of the radial surface velocity is different from the one in the surrounding areas. When incorporating this Doppler information into the wind retrieval algorithm, we obtain the wind field map depicted in Figure 7(b), which shows that in the wind tongue the wind was blowing in a northwesterly direction. It also agrees with wind measurements made at the weather station in Tuapse. This station measured at 0600 and 0900 UTC (1000 and 1300 local time) winds of 5-6 $\mathrm{m} \mathrm{s}^{-1}$ blowing from the south-southeast.

When comparing the near-surface wind fields (Figures 6(a), (b), and 7(b)) calculated using the three wind retrieval algorithms with the simulated wind field depicted in Figure 8, we see that outside the wind tongue area, the wind field derived from the ASAR image using linear features (LG method, Figure 6(b)) matches best the simulated wind field. But inside this area, it yields offshore winds, which are opposite to the wind direction calculated using the model (Figure 8). Also, here, the wind field derived from the SAR image using the NCEP model shows onshore winds (Figure 6(a)). Outside this area, the wind directions retrieved from the ASAR image agree reasonably well, in general, with the directions simulated by the model.

However, there are some areas where the wind fields disagree. One of these areas is the area marked A in Figures 6(a) and (b). Here, the wind field in Figure 7(b) is lower than in Figure 6(b). The reason is that the (wrong) direction of the NCEP model wind enters into the wind retrieval algorithm including Doppler shift as described in Section 4, which leads to underestimation of the wind speed. As we will state later in 'Summary and conclusions' section, the best algorithm to retrieve near-surface wind fields from SAR images in the future will be an algorithm, which incorporates not the wind direction provided by a model, but the direction inferred from both linear features and the Doppler shift. Another area where the wind fields disagree is the coastal area north of the wind tongue. The SAR-derived wind map depicted in Figure 7(b) shows weak onshore winds, which are in disagreement with the other SAR-derived wind fields (Figures 6(a) and (b)) and the model wind field (Figure 8). The reason for this disagreement could be that in this area, the Doppler shift receives a considerable contribution from a surface current, which has not been taken into account in the wind retrieval algorithm. Indeed, the surface current map depicted in Figure 9 calculated using the navy coastal ocean model (NCOM) (http://www7320. nrlssc.navy.mil/global_ncom/glb8_3b/html/index.html) for 0000 UTC on 22 June 2011 shows an onshore surface current in this area.

\subsection{The wind event on 13 September 2010}

Figure 10 shows a subscene of the ENVISAT ASAR WSM (VV polarization) image, which was acquired over the Black Sea at 0746 UTC (1146 local standard time) on 13 September 2010 during a descending satellite pass (see the inset). Visible are radar signatures of an atmospheric cyclonic eddy, marked by 'E', and of a foehn wind, marked by ' $F$ '. The foehn wind blows through the Kolkhida Lowland in the southwestern Caucasus (Western Georgia) onto the Black Sea (for more details see Alpers, Ivanov, and Dagestad 2011). The atmospheric eddy results from a positive vorticity advection over the eastern section of the Black Sea as evidenced by the $300 \mathrm{hPa}$ pressure chart valid for 0600 UTC on 13 September 2010 (not reproduced here). The cyclonic atmospheric eddy causes lifting of air and thus a decrease in air pressure at the sea surface. Thus, warm air at low levels spirals into the low pressure centre and is forced to rise. As it rises, it cools and forms a spiralling cloud pattern, which is confirmed by the cloud image (a colour composite) depicted in Figure 11(a). This 
image was acquired in the visible band by the Moderate Resolution Imaging Spectroradiometer (MODIS) aboard the Terra satellite at 0830 UTC on 13 September 2010, showing a cyclonic eddy in the cloud pattern (the red arrow points to its centre) in the eastern section of the Black Sea. The cyclonic atmospheric eddy also caused an oceanic response, giving rise to a cyclonic surface current pattern as evidenced by the surface current field (Figure 11(b)) calculated using the NCOM model for 0000 UTC on 13 September 2010.

Figure 12(a) shows the near-surface wind field derived from this ASAR image using the wind direction from the NCEP model for 0900 UTC on 13 September 2010, i.e. 1 hour and 28 min after the ASAR image was taken, and Figure 12(b) shows the one derived from the ASAR image using linear features for wind direction determination (LG method). Here, we focus on the wind direction in an area at the east coast of the Black Sea marked by red arrows. The wind directions retrieved from the ASAR image using the NCEP model (Figure 12(a)) and linear features (Figure 12(b)) differ considerably. The first map shows onshore winds, while the second one shows winds blowing along the coast.

In Figure 13(a), the radial surface velocity inferred from the Doppler shift is depicted. Blue colours denote negative and green/brownish colours denote positive radial velocities. When incorporating this Doppler information into the wind retrieval algorithm, we obtain the wind field map depicted in Figure 13(b), which, in the southern section, closely resembles the wind field retrieved from the SAR image using linear features (Figure 12 (b)). In particular, in the foehn wind area (marked by ' $F$ ' in Figure 10), the wind blows in a westerly direction, and further to the south, it blows in an easterly direction.

Furthermore, also the wind direction in the area near the east coast marked by a red arrow agrees well with the wind direction retrieved from the ASAR image using linear features (Figure 12(b)). However, the algorithm using linear features shows, in the northwestern section, winds blowing in a southeasterly direction, while the other two algorithms show winds blowing in the opposite direction.

When comparing the near-surface wind fields (Figures 12(a), (b), and 13(b)) calculated using the three wind retrieval algorithms with the simulated wind field depicted in Figure 14, we see that the wind field retrieved from the ASAR image using Doppler information matches best the model wind field, with one exception in the area marked by an ellipse in Figure 14. Neither this SAR-derived wind field, nor the ones derived using the two other algorithms show strong offshore winds in this area. The second best agreement is achieved by the algorithm using linear features. But, as mentioned already above, it yields in the northwestern section of the imaged scene, a wind that blows in a southern direction, which is opposite to the wind direction retrieved by the algorithm using Doppler information. Also, the algorithm using the NCEP model yields in this area winds blowing in a northerly direction. However, this algorithm has the deficiency that it does not catch well the position and shape of the cyclonic eddy, which we attribute to the coarse resolution of the model and to the fact that the wind direction used in the model is from a time which is 1 hour and 19 min earlier than the time of the SAR data acquisition.

\section{Summary and conclusions}

In this article, we have used three algorithms to retrieve near-surface wind fields from C-band synthetic aperture radar images acquired over the Black Sea. We have applied them to three complex wind fields imaged by the ASAR on board the ENVISAT and have compared the SAR-derived near-surface wind fields with model wind fields calculated using the high-resolution WRF model provided by the National Centres for 
Environmental Prediction.

We have shown that the near-surface wind fields retrieved from the SAR images using three different wind retrieval algorithms can yield quite different results in some areas. The algorithm using wind directions from an atmospheric model as input strongly depends on the quality of the model and can, in general, not reproduce such complex wind events in time and space as investigated in this article. The wind direction retrieval based on linear features has to rely on the presence of such features in SAR images as well as on additional information to resolve the $180^{\circ}$ directional ambiguity. The directional ambiguity can sometimes be resolved when wind shadows behind islands or coastal mountains are visible in SAR images.

Important progress in resolving this ambiguity has been made recently by including Doppler information in the wind retrieval algorithm (Mouche et al. 2012). This study has focused on this new algorithm.

However, retrieving wind information from Doppler shifts inherent in the backscattered radar signal is not straightforward, since the Doppler shift receives contributions from the drift induced by the wind on the sea surface (wind drift), sea state, and ocean surface currents (Johannessen et al. 2008). Wind drift and sea state depend on the nearsurface wind field, and thus these two contributions are used to estimate the wind speed and wind direction in the look direction of the SAR antenna. The Doppler-based algorithm relies on the good separation between contributions to the Doppler shift from near-surface winds and surface currents.

When the wind blows in the azimuth direction (parallel or anti-parallel to the flight track), the Doppler is expected to be zero. In these cases, this information can be very useful for retrieving other geophysical parameters from the Doppler than ocean surface winds, such as ocean surface currents, by minimizing the impact of the wind. However, it also adds noise into the wind retrieval algorithm. In such cases, the incorporation of linear wind-related features (often) visible in SAR images into the algorithm greatly helps to retrieve ocean surface wind fields from SAR data. For instruments having the capability to view the ocean surface at multiple azimuth angles, such as scatterometers or the future Wavemill instrument (Buck 2004), the Doppler-zero singularity is of less significance for wind field retrieval, but may allow coherent inversion to get both wind and current at the different viewing angles. Note that from areas of very low wind speed, where the backscattered radar signal is below the noise level of the instrument, no Doppler information can be retrieved.

In this article, we have assumed that the two geophysical model functions (GMFs) for the NRCS (CMOD) and for the Doppler (CDOP) depend only on the wind speed and direction (via the sea surface roughness). In this case, both GMFs are closely related. However, in the presence of other geophysical phenomena such as ocean surface currents, the consistency between CDOP and CMOD will decrease. In this case, the algorithm presented in this article is not applicable and fails to predict the observed Doppler and NRCS. As shown by Mouche, Collard, and Kerboal (2010), using ASAR data acquired over the Agulhas current, the inconsistency between the measured Doppler and measured NRCS values, together with the wind solution, can be used to identify areas with ocean surface currents. Furthermore, it can also be used to flag the quality of the wind inversion algorithm.

In the absence of ocean surface currents, the principal contribution to the Doppler shift is due to the ocean waves that are in equilibrium with the surface wind. Because the tilting of the smaller waves by longer waves decreases with incidence angle, the wind-induced Doppler shift also decreases with the incidence angle. Thus, measurements carried out at large incidence angles are best suited for measuring the ocean surface currents. For wind field retrieval over areas with ocean surface currents, the weight of the current contribution can be minimized by first analysing the NRCS and the Doppler data at a lower 
resolution. This procedure is motivated by the fact that the scale of ocean surface current features is generally smaller than that for atmospheric phenomena. Subsequently, in order to obtain a high-resolution wind field, the first guess wind field (derived from the low resolution NRCS and Doppler data) is used in a Bayesian scheme with the NRCS data at the higher resolution $(1 \mathrm{~km})$ as input. This scheme assumes that NRCS data are less affected by ocean surface currents than by Doppler data.

Finally, we would like to stress that this study does not deal with extreme meteorological situations such as hurricanes. Previous studies have revealed the ability of SAR to capture the circular patterns of the wind flow in hurricanes (Mouche, Collard, and Kerboal 2010) and in low-pressure systems (Mouche et al. 2012). However, for those extreme events, the different contributions to the backscattered radar signal are not yet fully understood. In particular, the contribution of swell generated by hurricanes (before the time of the SAR data acquisition) can have a significant impact on the Doppler shift (and also on the NRCS). Dedicated studies to this subject have to be undertaken to understand further the different geophysical contributions to the Doppler shift for such extreme cases.

In order to overcome the deficiencies inherent in the presently available wind retrieval algorithms, we are working on a next generation wind retrieval algorithm, which incorporates the wind direction determination by both linear features and Doppler information.

\section{Acknowledgements}

We thank NERSC in Bergen, Norway, for providing the wind fields depicted in Figures 2(a), 6(a), and 12(a) from their SAR archive, which were calculated from ASAR images using CMOD4 and NCEP.

\section{Funding}

The study was supported by the EC 7th Framework Programme (FP7/2007-2013) (project COCONET) [grant number 287844], and partly by the Russian Government [grant number 11.G34.31.0078] for research under the supervision of the leading scientists at the Russian State Hydrometeorological University.

\section{References}

Alpers, W., and B. Brümmer. 1994. "Atmospheric Boundary Layer Rolls Observed by the Synthetic Aperture Radar aboard the ERS-1 Satellite.” Journal of Geophysical Research 99 (C6):12613-12621. doi:10.1029/94JC00421.

Alpers, W., A. Y. Ivanov, and K.-F. Dagestad. 2010. "Observation of Local Wind Fields and Cyclonic Atmospheric Eddies over the Eastern Black Sea Using Envisat Synthetic Aperture Radar Images.” Issledovanie Zemli iz Kosmosa 5: 46-58.

Alpers, W., A. Y. Ivanov, and K.-F. Dagestad. 2011. "Encounter of Foehn Wind with an Atmospheric Eddy over the Black Sea as Observed by the Synthetic Aperture Radar Onboard Envisat.” Monthly Weather Review 139: 3992-4000. doi:10.1175/MWR-D-11-00074.1.

Alpers, W., A. Y. Ivanov, and J. Horstmann. 2009. “Observations of Bora Events over the Adriatic Sea and Black Sea by Spaceborne Synthetic Aperture Radar." Monthly Weather Review 137:1150-1161. doi: 10.1175/2008MWR2563.1. 
Buck, C. 2004. “The Wavemill Concept.” ESA Technical Note, Ref. TEC-

ETP/2004.121/CBu. https://directory.eoportal.org/web/eoportal/airborne-sensors/wavemill.

Chapron, B., F. Collard, and F. Ardhuin. 2005. "Direct Measurements of Ocean Surface Velocity from Space: Interpretation and Validation.” Journal of Geophysical Research 110 (C7).doi:10.1029/2004JC002809.

Dagestad, K.-F., J. A. Johannessen, G. Hauge, V. Kerbaol, and F. Collard. 2007. "Automated High Resolution Wind Field Retrievals off the Norwegian Coast by Combined Use of Envisat ASAR and Numerical Models." Proceedings of the Envisat Symposium 2007, Montreux, April 23-27 (ESA SP-636, July 2007).

Etling, D., and R. Brown. 1993. "Roll Vortices in the Planetary Boundary Layer: A Review." Boundary Layer Meteorology 65 (3): 215-248. doi:10.1007/BF00705527.

Hersbach, H., A. Stoffelen, and S. Dehaan. 2007. "An Improved C-Band Scatterometer Ocean Geophysical Model Function: CMOD5.” Journal of Geophysical Research 112: C03006. doi:10.1029/2006JC003743.

Horstmann, J., W. Koch, S. Lehner, and R. Tonboe. 2002. "Ocean Winds from RADARSAT1 Scansar." Canadian Journal of Remote Sensing 28: 524-533. doi:10.5589/m02-043.

Horstmann, J., S. Lehner, W. Koch, and R. Tonboe. 2000. "Computation of Wind Vectors over the Ocean Using Spaceborne Synthetic Aperture Radar." John Hopkins Applied Physics Laboratory Technical Digest 21: 100-107.

Johannessen, J. A., B. Chapron, F. Collard, V. Kudryavtsev, A.Mouche, D. Akimov, and K.F. Dagestad. 2008. "Direct Ocean Surface Velocity Measurements from Space: Improved Quantitative Interpretation of Envisat ASAR Observations." Geophysical Research Letters 35: L22608. doi:10.1029/2008GL035709.

Kain, J. S. 2004. “The Kain-Fritsch Convective Parameterization: An Update.” Journal of Applied Meteorology 43: 170-181. doi:10.1175/1520

0450(2004)043<0170:TKCPAU>2.0.CO;2.

Keller, W. C., W. J. Plant, R. A. Petitt, and E. A. Terray. 1994. "Microwave Backscatter from the Sea: Modulation of Received Power and Doppler Bandwidth by Long Waves." Journal of Geophysical Research 99 (C5): 9751-9766. doi:10.1029/94JC00082.

Koch, W. 2004. "Directional Analysis of SAR Images Aiming at Wind Direction." IEEE Transactions on Geoscience and Remote Sensing 42: 702-710. doi:10.1109/ TGRS.2003.818811.

Kudryavtsev, V., V. D. Hauser, G. Causdal, and B. Chapron. 2003. "A Semi-Empirical Model of the Normalized Radar Cross-Section of the Sea Surface - 1. Background Model." Journal of Geophysical Research 108 (C3): 804. doi:10.1029/2001JC001003.

Lehner, S., J. Horstmann, W. Koch, and W. Rosenthal. 1998. "Mesoscale Wind Measurements Using Recalibrated ERS SAR Images.” Journal of Geophysical Research 103 (C4): 7847-7856. doi:10.1029/97JC02726. 
Monaldo, F., V. Kerbaol, and the SARWind Team. 2003. "The SAR Measurement of Ocean Surface Winds: An Overview." In Proceedings of the 2nd Workshop on Coastal and Marine Applications of SAR, Svalbard.

http://earth.esa.int/workshops/cmasar_2003/papers/E02mona.pdf.

Monaldo, F. M., D. R. Thompson, R. C. Beal, W. G. Pichel, and P. Clemente-Colón. 2001. "Comparison of SAR Derived Wind Speed with Model Predictions and Ocean Buoy Measurements." IEEE Transactions on Geoscience and Remote Sensing 39: 2587-2600. doi:10.1109/36.974994.

Mouche, A., F. Collard, and V. Kerboal. 2010. "Recent Progress in SAR Wind Direction Retrieval on the Use of Doppler Anomaly for SAR Winds." Proceedings of the Third International Workshop SeaSAR 2010, ESA ESRIN, Frascati, January 25-29. ESA Publication SP-679 (on CD-ROM). http://earth.eo.esa.int/workshops/seasar2010/participants/565/pres_565_alexis.pdf.

Mouche, A. A., F. Collard, B. Chapron, K.-F. Dagestad, G. Guitton, J. A. Johannessen, V. Kerbaol, and M. W. Hansen. 2012. "On the Use of Doppler Shift for Sea Surface Wind Retrieval from SAR." IEEE Transactions on Geoscience and Remote Sensing 50: 2901-2909. doi:10.1109/TGRS.2011.2174998.

Müller, G., B. Brümmer, and W. Alpers. 1999. "Roll Convection within an Arctic Cold-Air Outbreak: Interpretation of in Situ Aircraft Measurements and Spaceborne SAR Imagery by a Three-Dimensional Atmospheric Model." Monthly Weather Review 127: 363-380. doi:10.1175/1520-0493(1999)127<0363:RCWAAC >2.0.CO;2.

Portabella, M., A. Stoffelen, and J. A. Johannessen. 2002. “Toward an Optimal Inversion Method for Synthetic Aperture Radar Wind Retrieval.” Journal of Geophysical Research 107 (C8): 3086. doi:10.1029/2001JC000925.

Rouault, M. J., A. Mouche, F. Collard, J. A. Johannessen, and B. Chapron. 2010. "Mapping the Agulhas Current from Space: An Assessment of ASAR Surface Current Velocities." Journal of Geophysical Research 115: C10026. doi:10.1029/2009JC006050.

Skamarock, W. C., J. B. Klemp, J. Dudhia, D. O. Gill, D. M. Barker, M. G. Duda, X.-Y. Huang, W. Wang, and J. G. Powers. 2008. "A Description of the Advanced Research WRF Version 3." NCAR Tech Note NCAR/TN-4751STR, 113 pp. http://www.mmm.ucar.edu/wrf/users/docs/arw_v3 bw.pdf.

Stoffelen, A., and D. Anderson. 1997. "Scatterometer Data Interpretation: Estimation and Validation of the Transfer Function CMOD4." Journal of Geophysical Research 102 (C3): 5767-5780. doi:10.1029/96JC02860.

Valenzuela, G. R., 1978. "Theories for the Interaction of Electromagnetic and Oceanic Waves: A Review.” Boundary-Layer Meteorology 13: 61-85.

Wackerman, C. C., C. L. Rufenach, R. A. Shuchman, J. A. Johannessen, and K. L. Davidson. 1996. "Wind Vector Retrieval Using ERS-1 Synthetic Aperture Radar Imagery." IEEE Transactions on Geoscience and Remote Sensing 34: 1343-1352. doi:10.1109/36.544558. 
Wright, J. W. 1968. “A New Model for Sea Clutter.” IEEE Transactions on Antennas and Propagation 16: 217-223. doi:10.1109/TAP.1968.1139147.

Zecchetto, S., and F. De Biasio. 2008. "A Wavelet-Based Technique for Sea Wind Extraction from SAR Images." IEEE Transactions on Geoscience and Remote Sensing 46: 2983-2989. doi:10.1109/TGRS.2008.920967.

\section{Figures}

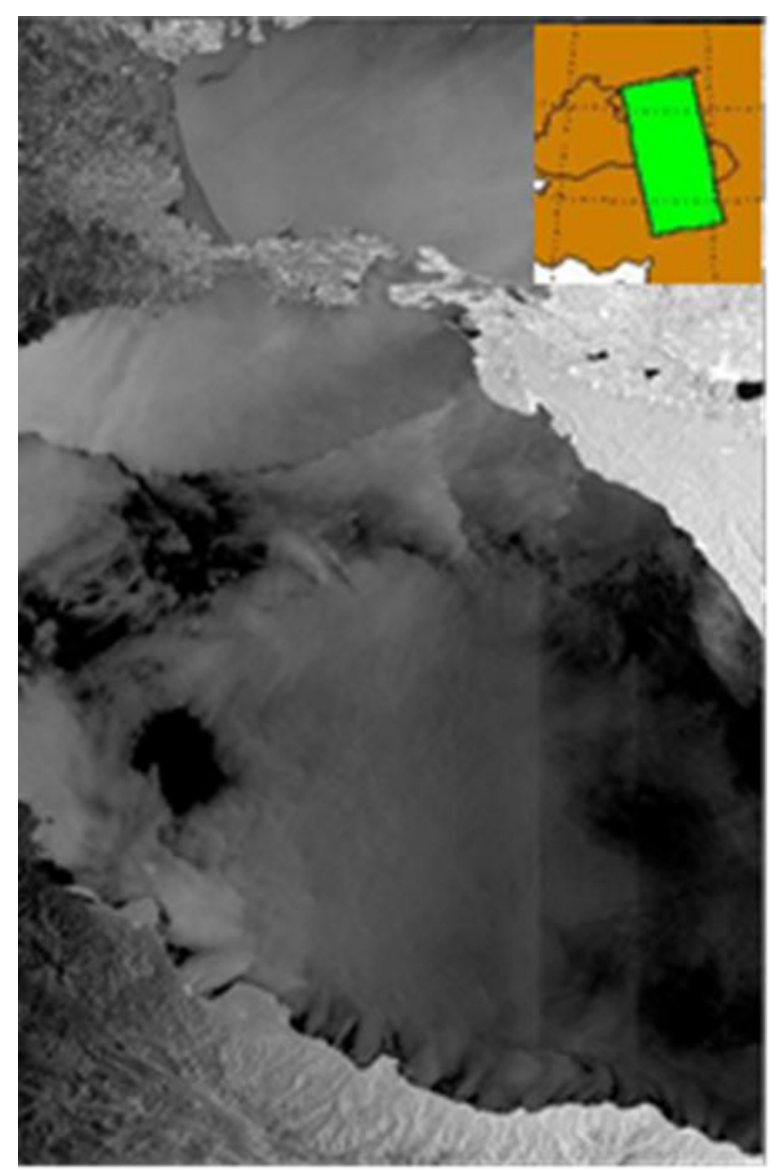

Figure 1. Section of an ASAR WSM image acquired by ENVISAT at 1919 UTC on 16 January 2011 over the eastern section of the Black Sea. The swath width is $400 \mathrm{~km}$. The inset shows the location of the complete SAR scene. (C) European Space Agency (ESA). 


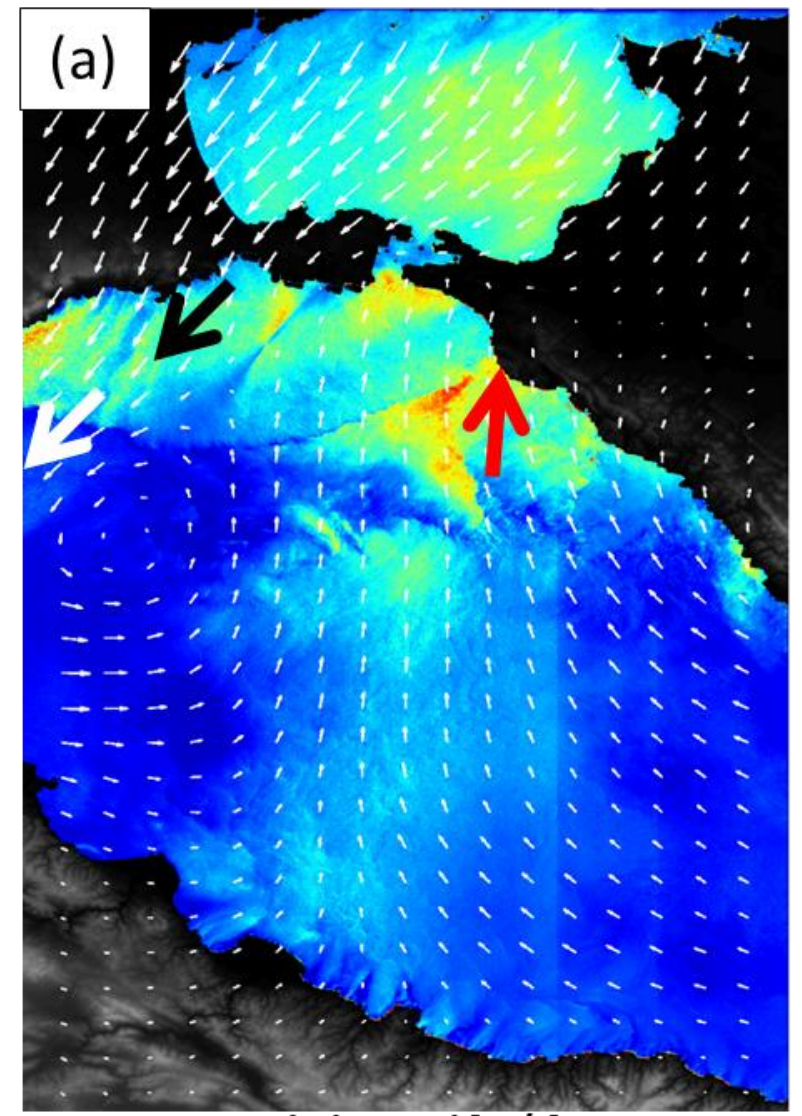

Wind Speed $[\mathrm{m} / \mathrm{s}]$

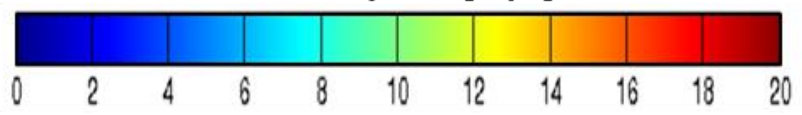

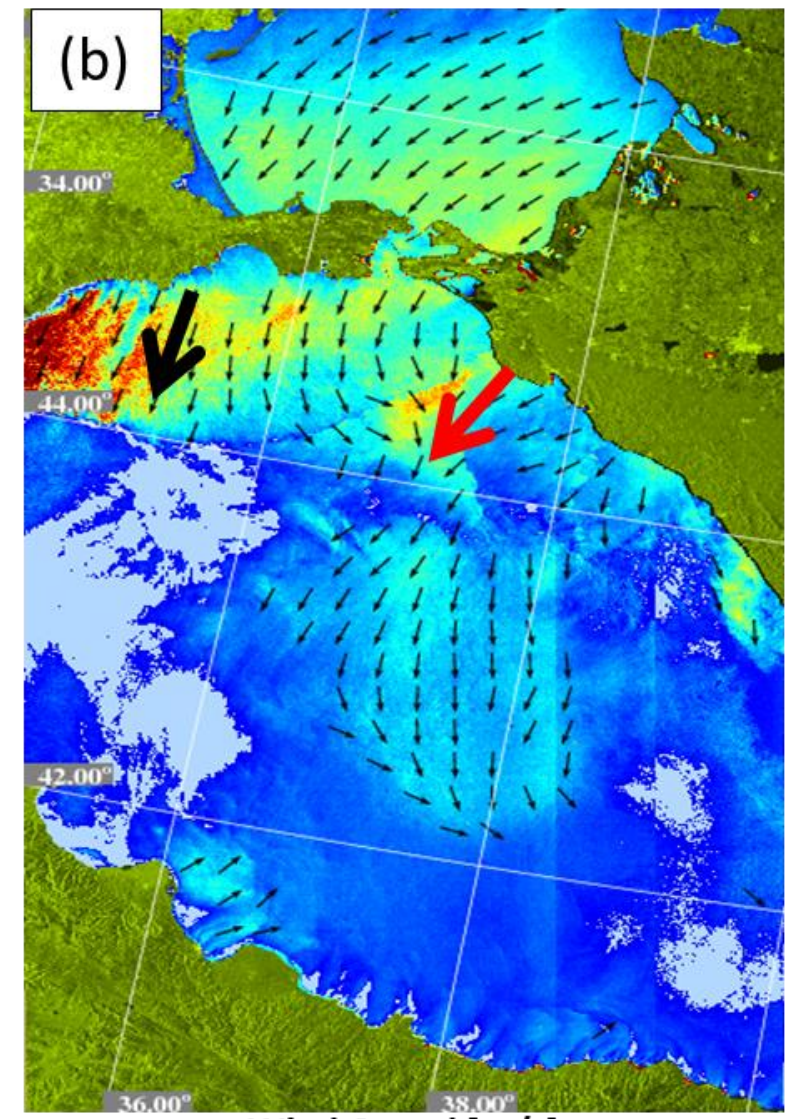

Wind Speed $[\mathrm{m} / \mathrm{s}]$

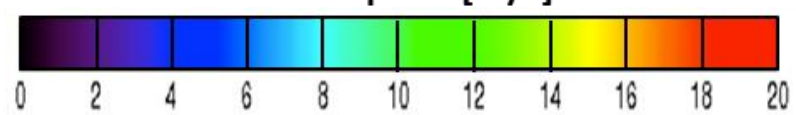

Figure 2. Near-surface wind fields derived from the ASAR image depicted in Figure 1 by taking the wind directions from the NCEP model 1 hour and 19 min before the SAR image was acquired (a) and from linear features (b). The arrows denote the wind directions at the respective locations. Note that on the left plot the wind blows onshore at the east coast, while on the right plot it blows offshore (red arrows). 

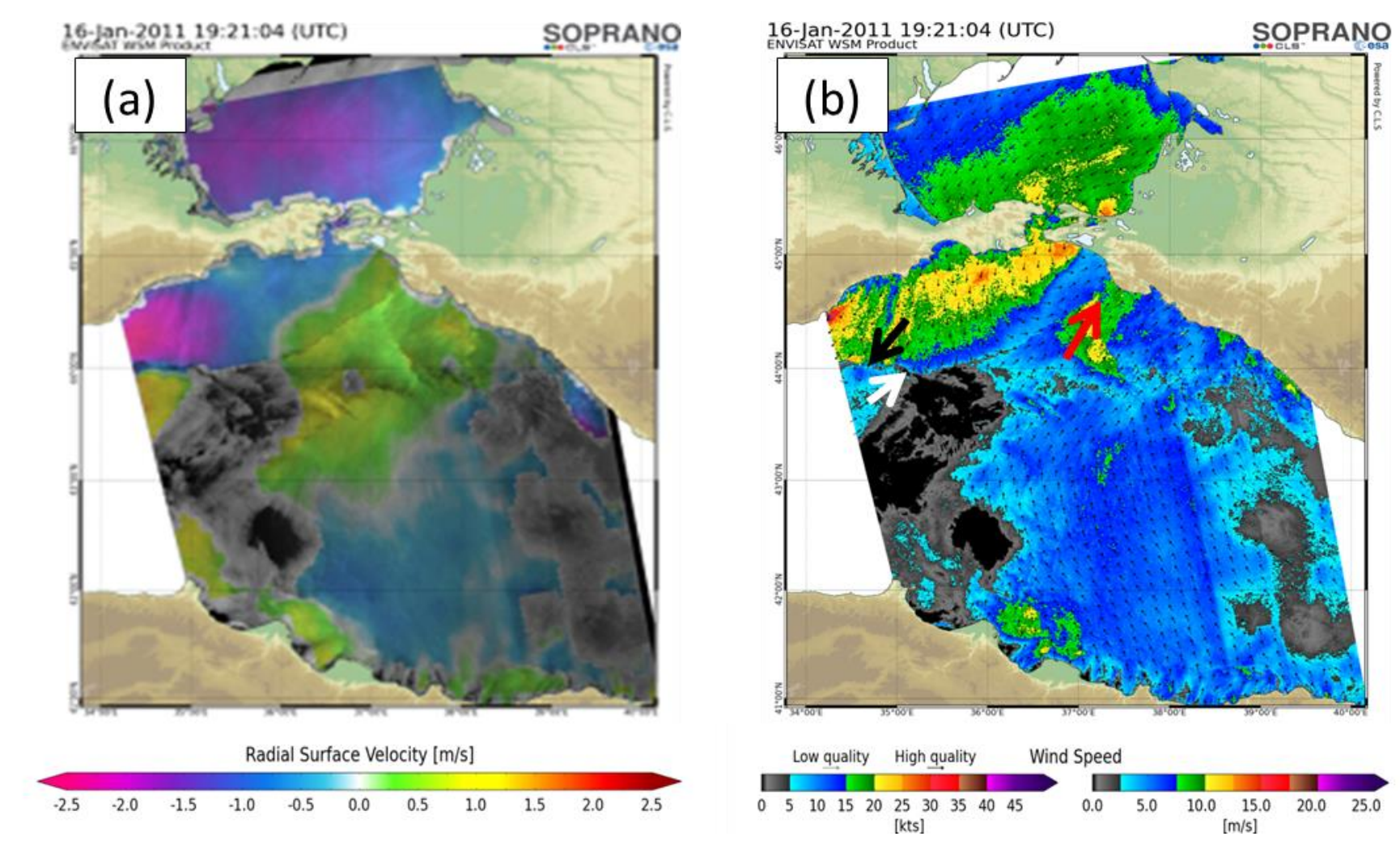

Figure 3. (a) Doppler velocity retrieved from the ASAR image. (b) Near-surface wind field derived from the ASAR image depicted in Figure 1 by including Doppler information in the wind retrieval algorithm. The arrows denote the wind directions at the respective positions. Note that to the west the wind blows from opposing directions on both sides of the front (marked by black and white arrows). 


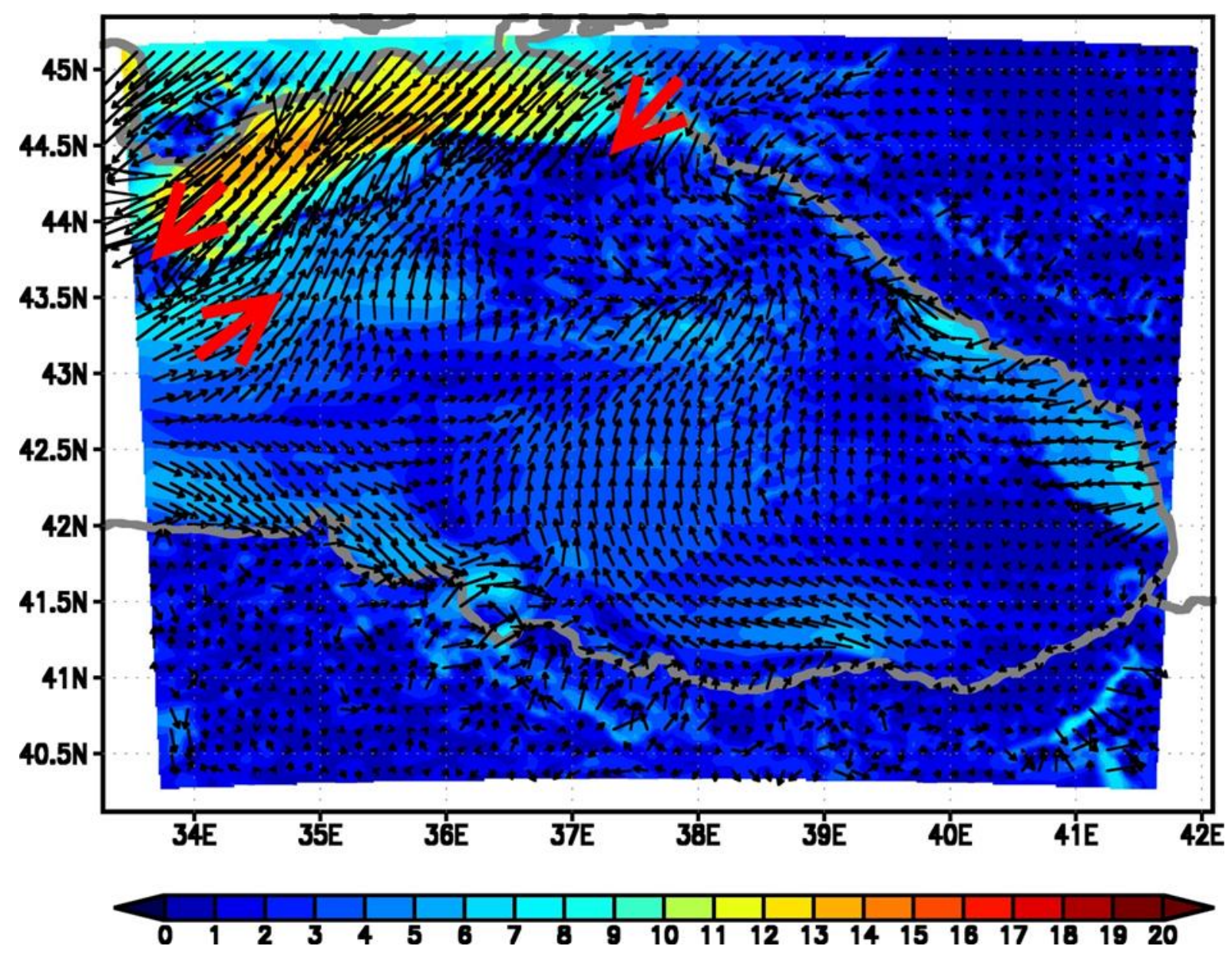

Figure 4. Wind field at the lowest level simulated using the WRF model for 1930 UTC on 16 January 2011 . The black arrows denote the wind direction. The wind directions at the locations marked in Figure 2 are highlighted by red arrows. 

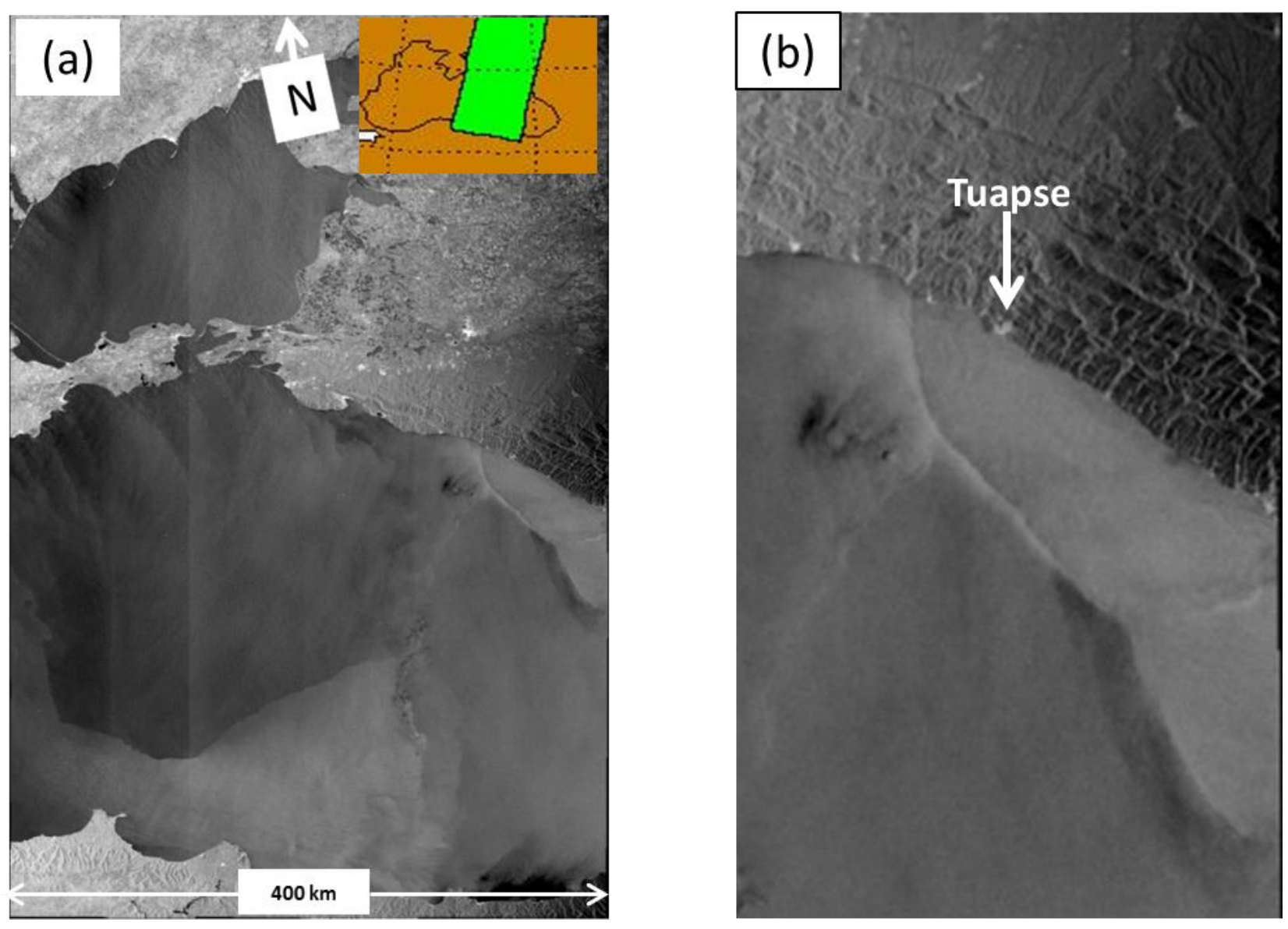

Figure 5. (a) Section of an ASAR WSM image acquired by ENVISAT at 0745 UTC on 21 June 2011 over the eastern section of the Black Sea. The swath width is $400 \mathrm{~km}$. The inset shows the location of the complete SAR scene. (b) Zoom on the bright band attached to the east coast. (C) ESA. 


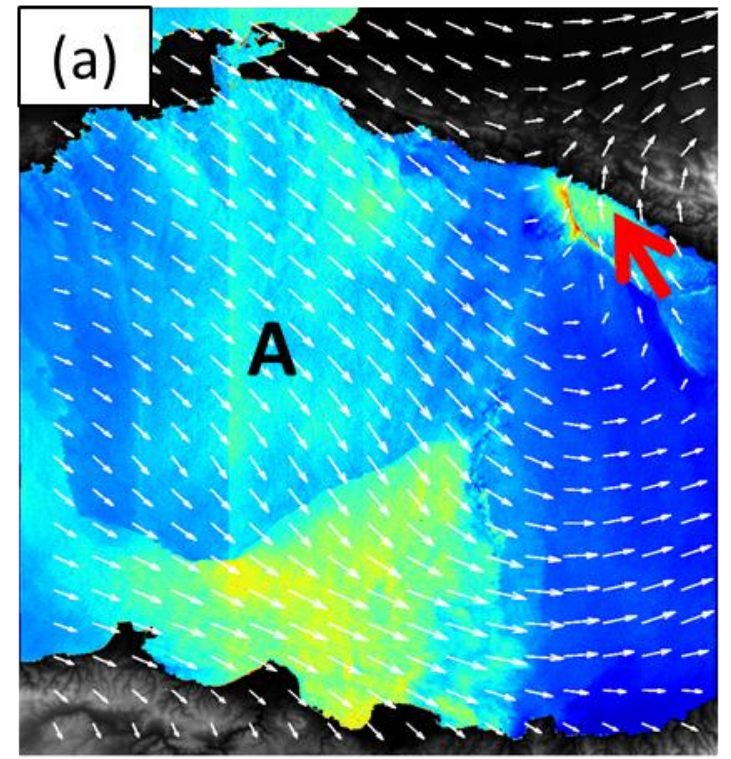

Wind Speed $[\mathrm{m} / \mathrm{s}]$

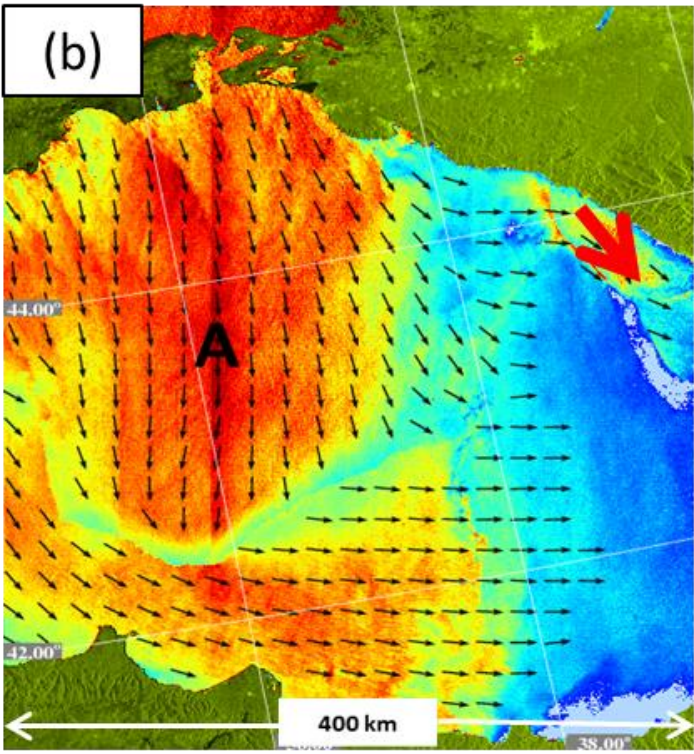

Wind Speed $[\mathrm{m} / \mathrm{s}]$
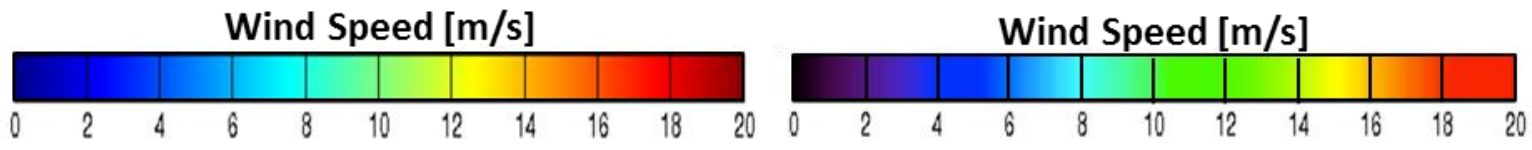

Figure 6. Near-surface wind field derived from the ASAR image depicted in Figure 5 by taking the wind directions from the NCEP model ( 1 hour and 14 min after the ASAR image was acquired (a) and from linear features (b)). The red arrows denote the wind directions at the 'wind tongue along the east coast, which are in opposite directions. 

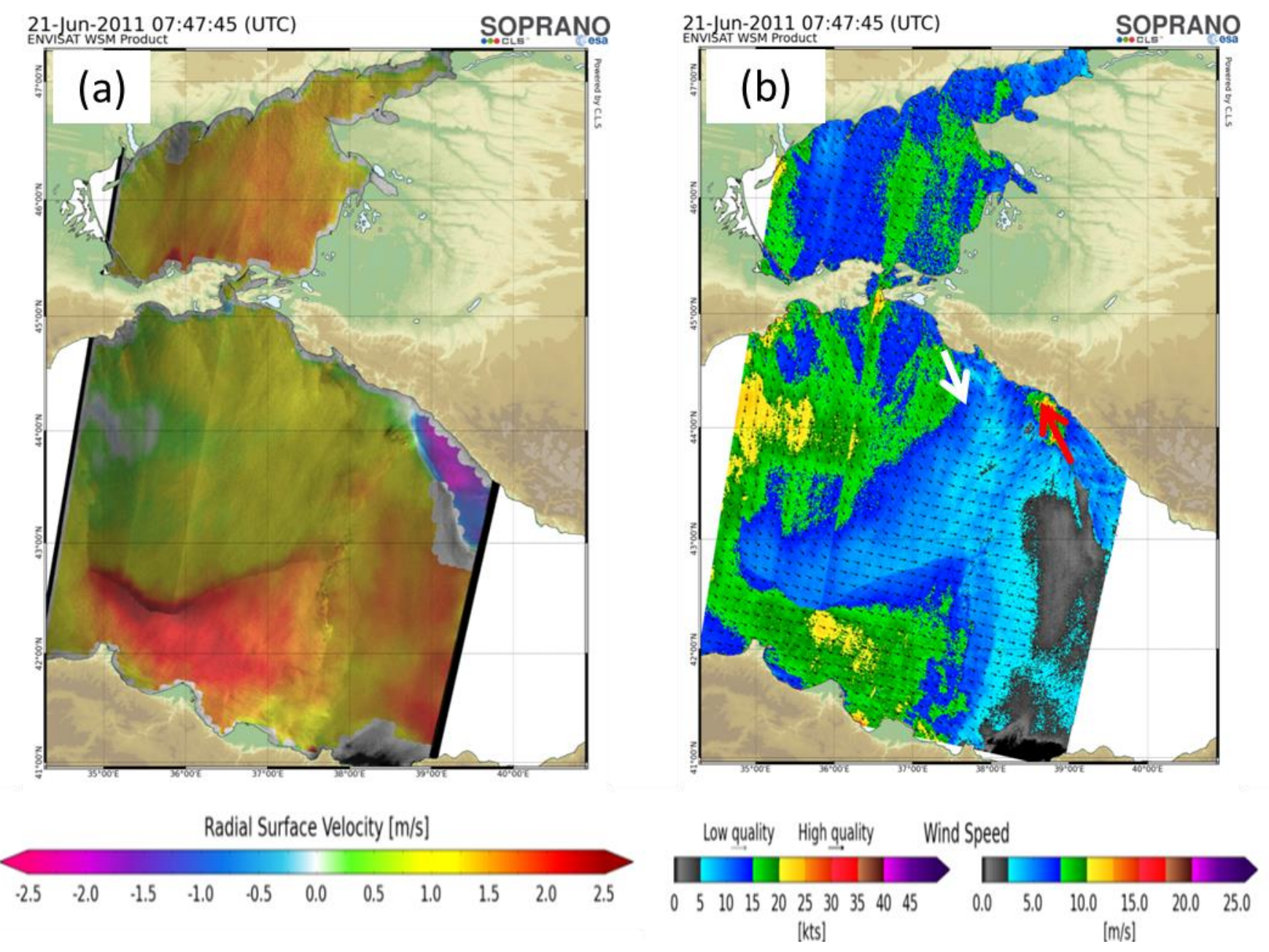

Figure 7. (a) Doppler velocity retrieved from the ASAR image. (b) Near-surface wind field derived from the ASAR image depicted in Figure 5 by including Doppler shift information in the wind retrieval algorithm. The arrow denotes the wind direction in the 'wind tongue'. 


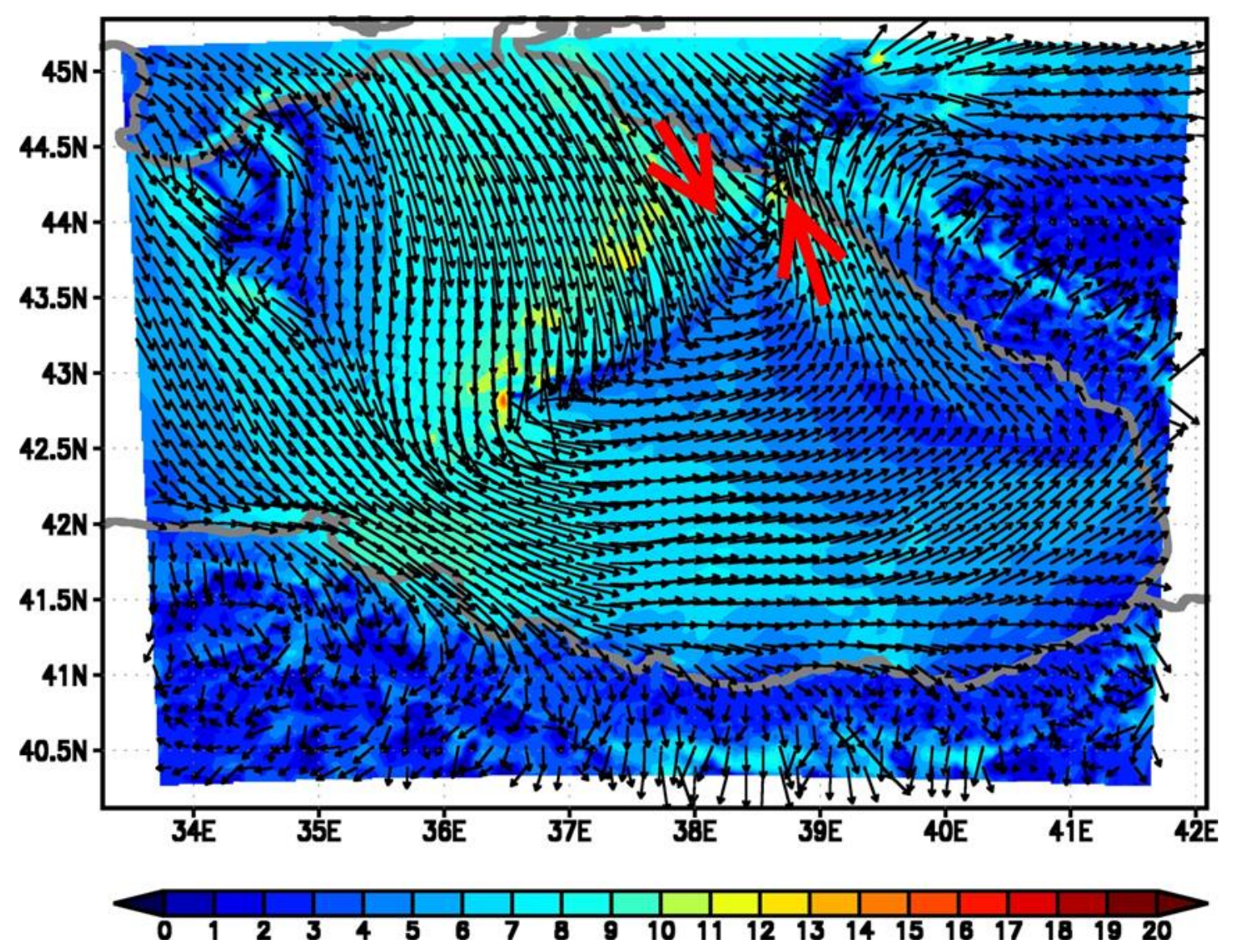

Figure 8. Wind field at the lowest level simulated using the WRFmodel for 0730 UTC on 21 June 2011. The black arrows denote the wind direction. The wind directions at the locations marked in Figure 7 are highlighted by red arrows. 


\section{Surface Currents over Speed $(\mathrm{cm} / \mathrm{s})$ NRL global NCOM glb8_3b $06-22-201100 \mathrm{Z}$ analysis $0000 \mathrm{~m}$}

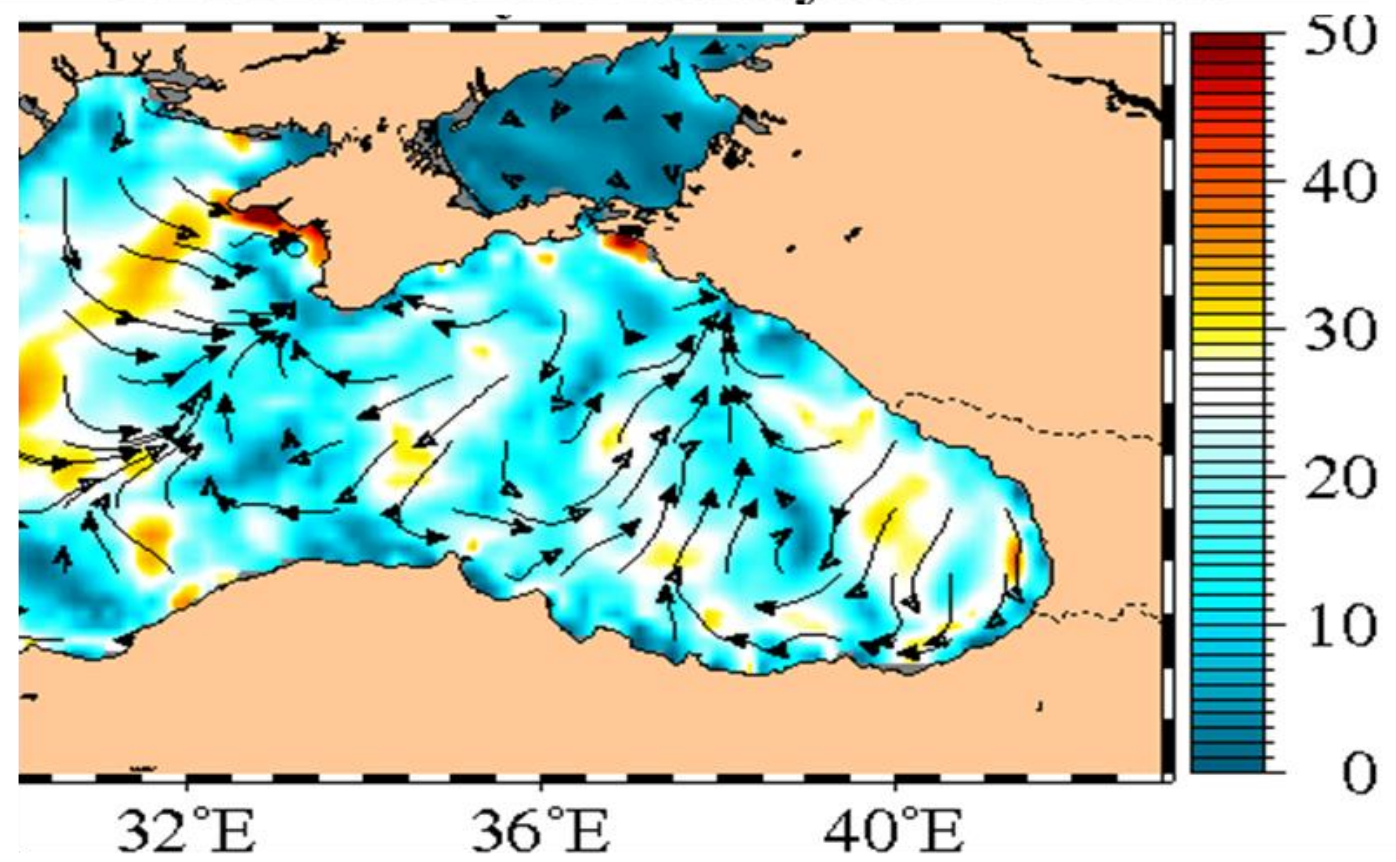

\section{Velocity Scale: $29 \mathrm{~cm} / \mathrm{s}$}

Figure 9. Surface-current field calculated using the NCOM model for 0000 UTC on 22 June 2011. Note the on-shore current at the northeast coast, north of the location of the bright band visible in the ASAR image (Figure 5) (surface currents over speed $\left(\mathrm{cm} \mathrm{s}^{-1}\right)$ NRL global NCOM glb8_3b 22 June 2011 00Z analysis $0000 \mathrm{~m}$ ). (C) NRL-NCOM. 


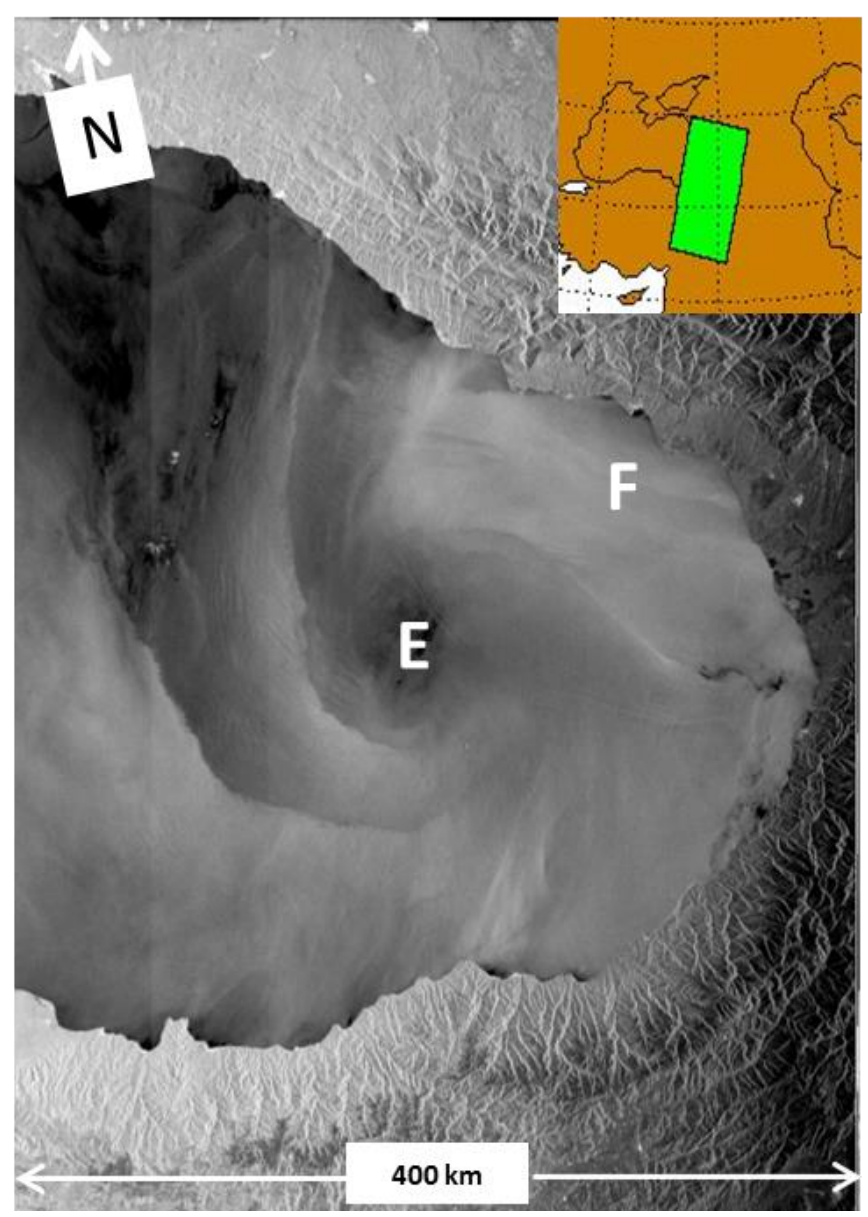

Figure 10. Section of an ASAR WSM image acquired at 0732 UTC on 13 September 2010 over the eastern Black Sea, showing radar signatures of a mesoscale atmospheric cyclonic eddy (the centre marked ' $E$ ') and a foehn wind (marked ' $F$ '). The imaged area is $400 \mathrm{~km} \times$ $480 \mathrm{~km}$. The inset shows the location of the SAR scene. (C) ESA. 

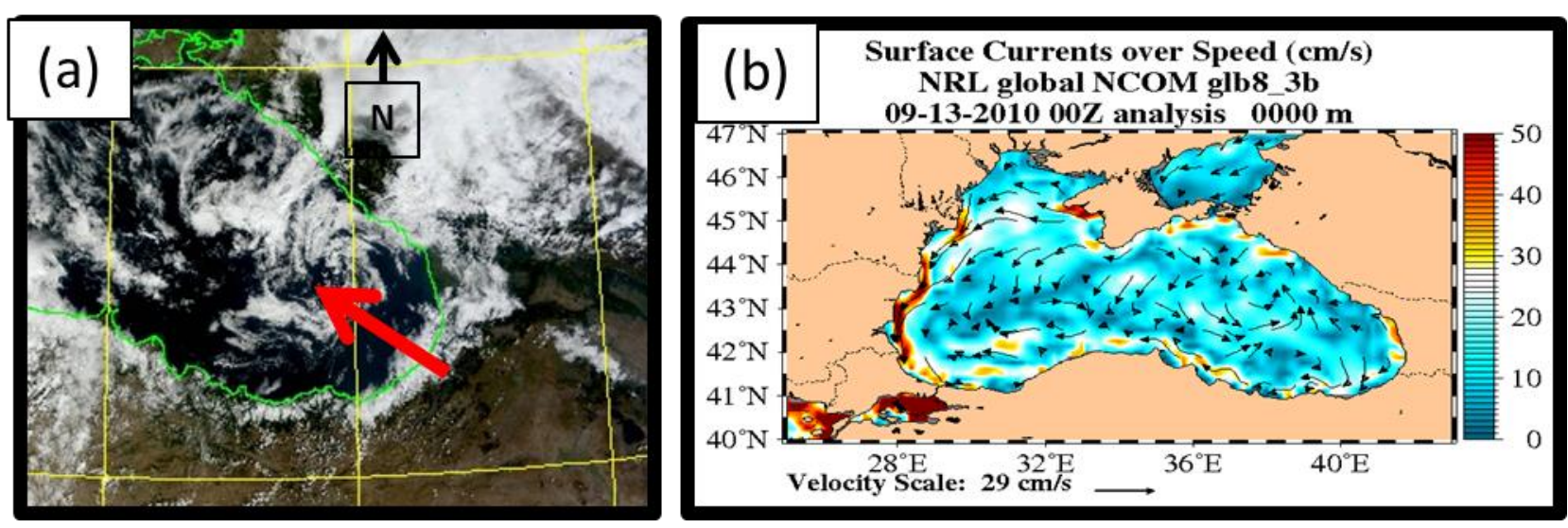

Figure 11. (a) MODIS Terra colour composite image acquired at 0830 UTC on 13 September 2010 showing a cyclonic eddy in the cloud pattern (the red arrow points to its centre) in the eastern section of the Black Sea. C) NASA GSFC. (b) Surface-current field calculated using the NCOM model for 0000 UTC on 13 September 2010 (surface currents over speed (cm s-1) NRL global NCOM glb8_3b 13 September 2010 00Z analysis 0000 m). (C) NRL-NCOM. Both the observed cloud distribution and the simulated surface current field show a cyclonic eddy pattern in the eastern section of the Black Sea with the centre close to the position marked 'F' in Figure 10. 


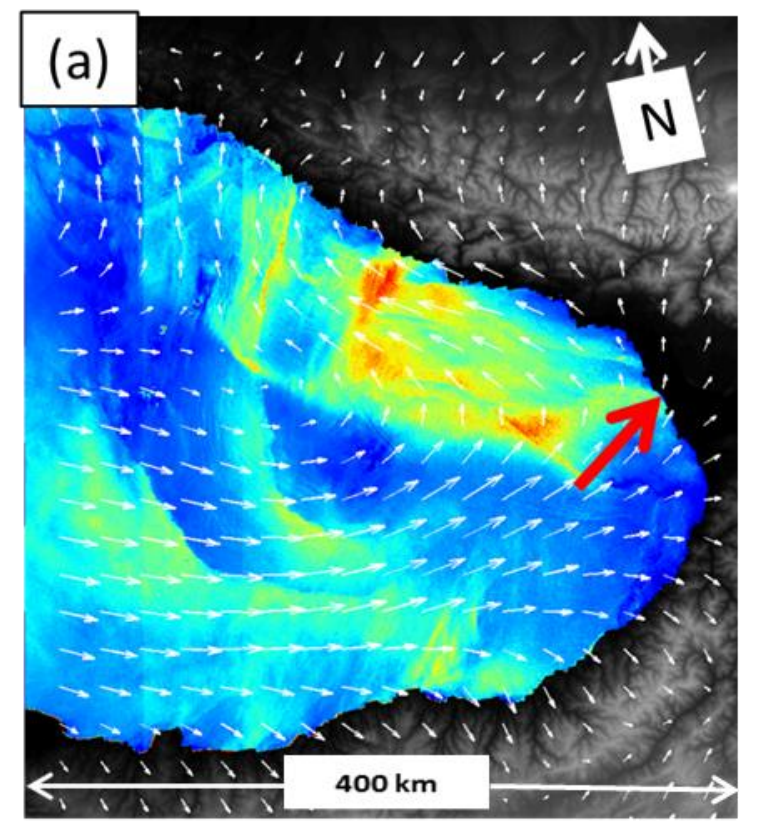

Wind Speed [m/s]

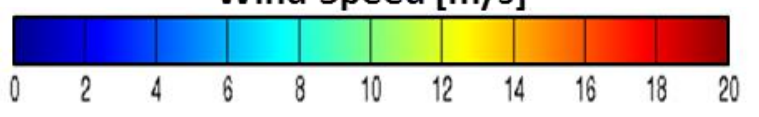

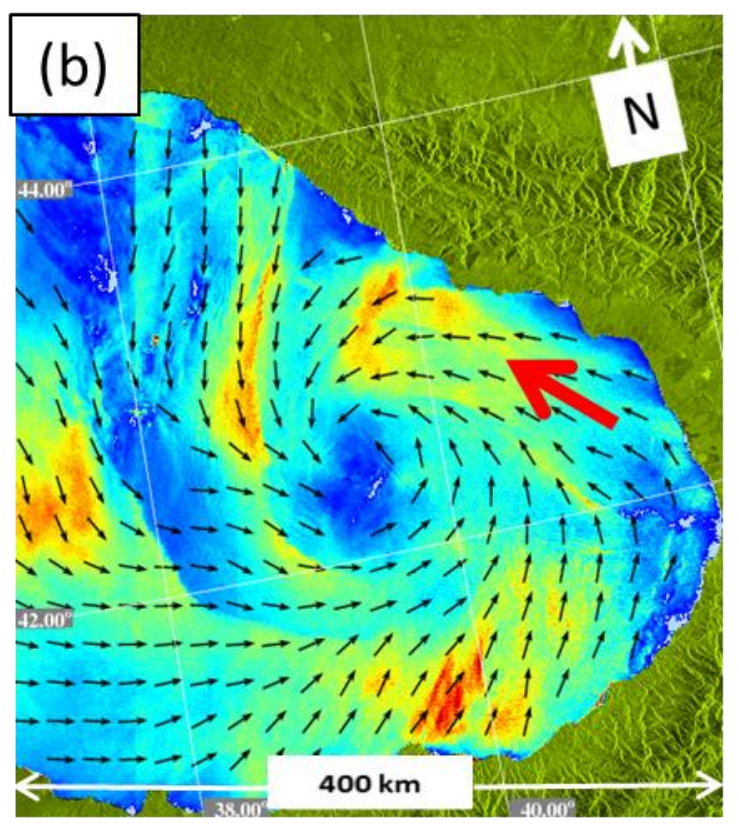

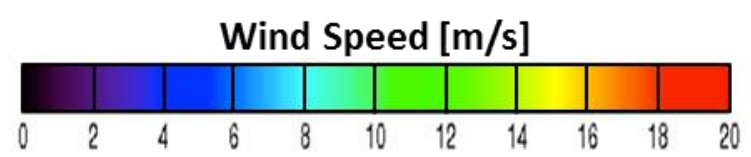

Figure 12. Near-surface wind field derived from the ASAR image (Figure 10) by taking the wind directions from the NCEP model 1 hour and 19 min before the SAR image was acquired (a) and from linear features (b). The red arrows denote the wind directions in an area along the east coast, which have different directions. 


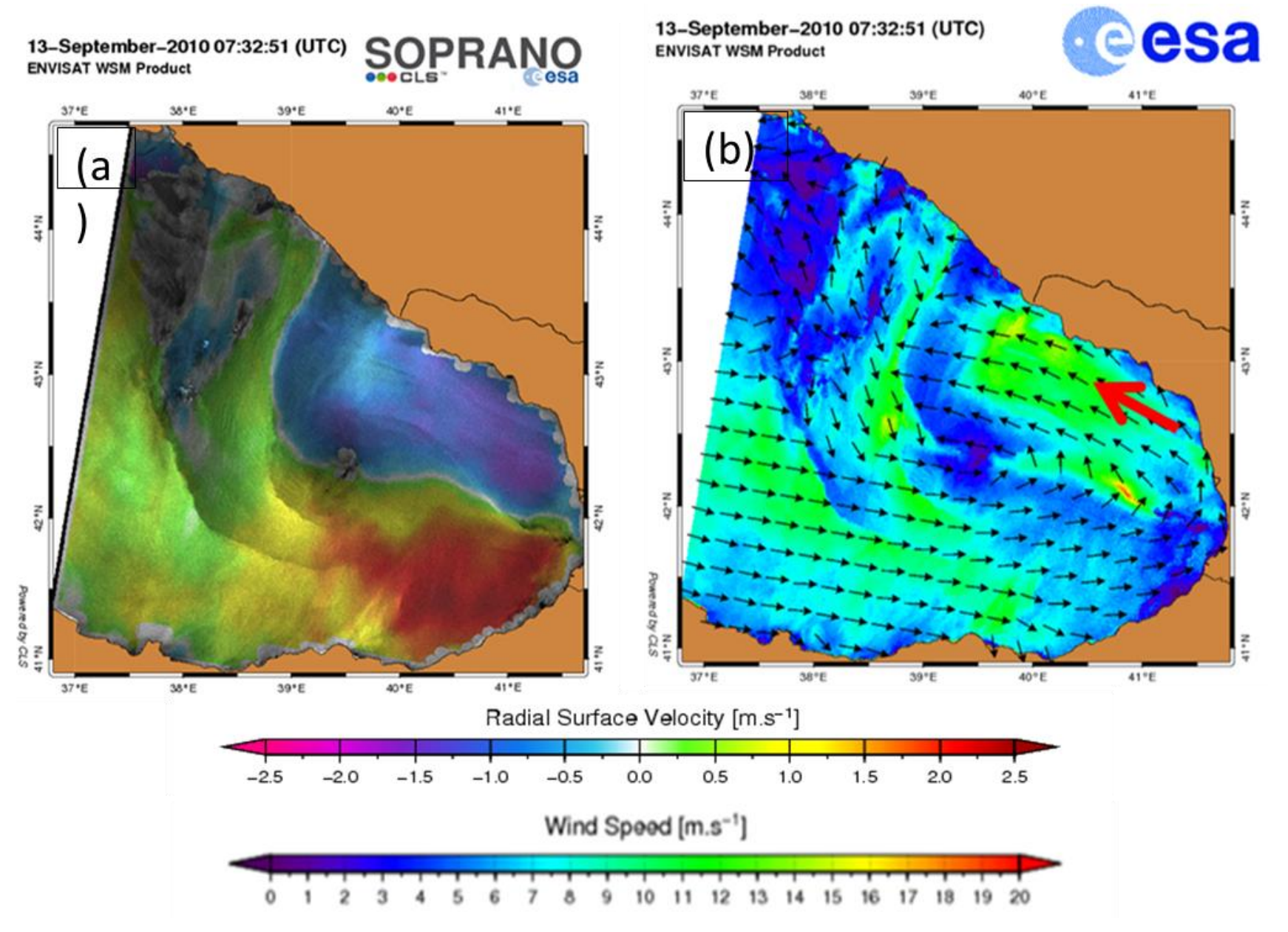

Figure 13. (a) Doppler velocity retrieved from the ASAR image. (b) Near-surface wind field derived from the ASAR image depicted in Figure 10 by including Doppler shift information in the wind retrieval algorithm. The arrow denotes the wind direction in an area along the east coast. 


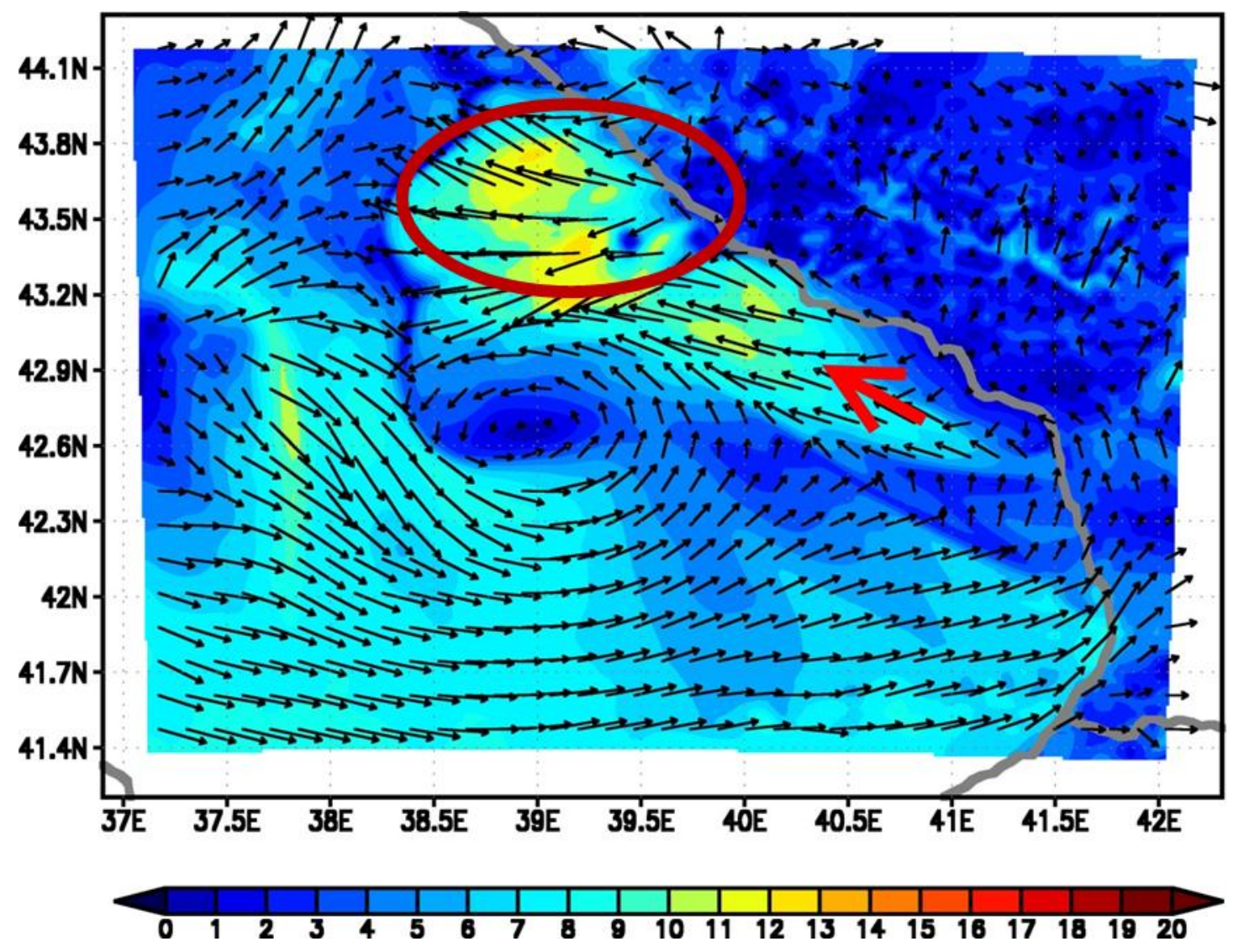

Figure 14. Wind field at the lowest level simulated using the WRF model for 0730 UTC on 13 September 2010. The black arrows denote the wind direction. The wind direction at the locations marked in Figures 12(a), (b) and 13(b) is highlighted by a red arrow. 